\title{
VIABILIDADE DA RECICLAGEM NO ESTADO DA PARAÍBA
}

\author{
Nadja Helaine de ARAÚJO'; Gil Dutra FURTADO²; Gabrielle Diniz dos SANTOS ${ }^{3}$
}

\author{
${ }^{1}$ Bióloga; Mestra em Manejo e Desenvolvimento de Meio Ambiente, Brasil \\ ${ }^{2}$ Graduando em Medicina Veterinária UNINASSAU/PB; Engenheiro Agrônomo/UFPB; Doutor em \\ Psicobiologia/UFRN; Sócio da Cooperativa de Agronegócio (COOPAGRO), Brasil. E-mail: \\ gdfurtado@ hotmail.com. \\ ${ }^{3}$ Bacharel em Ecologia, UFPB; Especialista em Planejamento Urbano e Gestão de Cidades, UNIPE; Mestre em \\ Desenvolvimento e Meio Ambiente (PRODEMA), UFPB, Brasil. E-mail: gabrielledsantos90@gmail.com
}

Resumo. Atualmente, os problemas enfrentados pela humanidade são consequências de um aumento desordenado da população, má distribuição de renda, falta de estruturação e compromisso por parte de alguns governantes e o crescente desequilíbrio ambiental que assola o mundo. No tocante ao desequilíbrio ambiental, a produção e a destinação inadequada do lixo tem provocado um excesso de resíduos sólidos, líquidos e gasosos que poluem a água, o solo e o ar. As políticas públicas ainda se tornam um desafio no Estado da Paraíba devido a demanda de resíduos e lixo que são produzidos diariamente. A coleta seletiva solidária realizada através dos catadores, que trabalham em forma de cooperativas, pode se tornar um exemplo de Políticas Públicas. Diante disso, o presente trabalho foi realizado através de pesquisas bibliográficas, com intuito de auxiliar na busca de novos caminhos para o destino dos resíduos. É necessário também que governantes, empresas privadas e comunidade em geral se mobilizem para atuar numa das mais simples e óbvias maneiras de encaminhar o lixo para um destino: A reciclagem. O papel da reciclagem nos dias de hoje é imprescindível, pois através dela podemos transformar algo até então inutilizado em arte, benefícios para a população, entre outros e ainda diminuir a quantidade de resíduos "indesejáveis".

Palavras-chave: Lixo; Desenvolvimento Sustentável; Políticas Públicas.

\section{VIABILITY OF RECYCLING IN THE STATE OF PARAÍBA}

Abstract. Today, the problems faced by humanity are the consequences of a disorderly increase in population, poor distribution of income, lack of structuring and commitment on the part of some rulers, and the growing environmental imbalance that plagues the world. Concerning the environmental imbalance, the production and improper disposal of waste has caused an excess of solid, liquid and gaseous wastes that pollute water, soil and air. Public policies still become a challenge in the state of Paraíba due to the demand for waste and garbage that are produced daily. The selective collection of solidarity carried out through the collectors, who work in the form of cooperatives, can become an example of Public Policies. Therefore, the present work was carried out through bibliographical researches, in order to help in the search of new ways for the waste destination. Governors, private companies and the community in general must also mobilize to act in 
one of the simplest and most obvious ways to send garbage to a destination: recycling. The role of recycling today is essential, because through it we can transform something previously unused in art, benefits to the population, among others and still reduce the amount of "unwanted" waste.

Keywords: Garbage; Sustainable Development; Public policy.

\section{VIABILIDAD DEL RECICLADO EN EL ESTADO DE LA PARAÍBA}

Resumen. Hoy en día, los problemas a los que se enfrenta la humanidad son las consecuencias de un aumento desordenado de la población, una distribución deficiente de los ingresos, la falta de estructuración y el compromiso de algunos gobernantes y el desequilibrio ambiental que afecta al mundo. En relación con el desequilibrio ambiental, la producción y la eliminación inadecuada de los desechos ha provocado un exceso de desechos sólidos, líquidos y gaseosos que contaminan el agua, el suelo y el aire. Las políticas públicas aún se convierten en un desafío en el estado de Paraíba debido a la demanda de desechos y basura que se producen diariamente. La colección selectiva de solidaridad llevada a cabo por los coleccionistas, que trabajan en forma de cooperativas, puede convertirse en un ejemplo de políticas públicas. Por lo tanto, el presente trabajo se llevó a cabo a través de investigaciones bibliográficas, con el fin de ayudar en la búsqueda de nuevas formas para el destino de los residuos. Los gobernadores, las empresas privadas y la comunidad en general también deben movilizarse para actuar de una de las formas más simples y obvias de enviar basura a un destino: el reciclaje. El papel del reciclaje hoy en día es esencial, ya que a través de él podemos transformar algo que anteriormente no se usaba en el arte, los beneficios para la población, entre otros, y aun así reducir la cantidad de desechos "no deseados".

Palabras clave: Basura; Desarrollo Sostenible; Políticas públicas.

\section{INTRODUÇÃO}

Uma das maiores preocupações a nível mundial diz respeito à destinação daquilo que é descartado por não ter mais utilidade, o lixo. Segundo Bartone (2001), lixo é todo material, orgânico ou não, produzido pela sociedade humana, que foi considerado inútil e indesejado e que deve ser eliminado. Pode ser definido também como aquilo que não tem valor funcional para algumas pessoas, as quais desejam tirá-lo da sua vista por enxerga-lo como algo sujo e repugnante.

Mas na realidade, o lixo faz parte da história do homem. Desde os tempos da Idade Média, o homem já se via envolto pela questão do lixo, principalmente quando este se acumulava nas ruas, provocando o aparecimento de pragas e pestes, causando a morte de inúmeras pessoas (BRANCO, 1983).

A questão ambiental que envolve a problemática do lixo é um tema bastante atual. Antigamente, a degradação do lixo era mais rápida devido à maioria dos resíduos produzidos 
serem de origem orgânica. Mas, foi a partir da urbanização e do êxodo rural, processos advindos da Revolução industrial, provocando o aumento da população nas cidades, trouxe como consequência negativa um aumento nos vários tipos de poluição, entre elas a elevação na produção de lixo, tornando-o um problema que deveria ter uma solução rápida e eficaz: surgiam os "lixões" (FADINI; FADINI, 2001).

Tratando-se em nível de Brasil, a problemática do lixo tem como principal questionamento a destinação dos resíduos. A saturação dos aterros sanitários, ou "lixões", complica ainda mais a situação. Porém, existem alguns métodos que podem minimizar o volume de lixo nesses locais, como incineração, digestão anaeróbia, compostagem, coleta seletiva ou separação pós-coleta. A reciclagem de materiais usados constitui-se em uma das principais soluções (BIANCHINI, 2001).

O Brasil possui uma das maiores reservas de recursos naturais do planeta, possui variedade climática e grande biodiversidade, mas a exploração desses recursos naturais, a cada dia torna-se mais intensa, devido ao crescimento populacional e principalmente por falta de infraestruturas básicas para receber essas populações. Dessa forma, agravam-se vários problemas como produção de lixo, poluição em todas as esferas ambientais, falta de saneamento básico e exploração descontrolada dos recursos naturais.

Apesar desse quadro assustador, a sociedade vem tomando consciência da importância de se conservar a natureza e de lutar pela melhoria na qualidade de vida. A população tem se preocupado com as questões ambientais e se mobilizando para amenizar os diversos impactos causados por ela perante a natureza. Uma dessas iniciativas é a coleta seletiva e a reciclagem de materiais.

Selecionar aquilo que pode ter um novo destino é o objetivo básico da coleta seletiva. Assim, aliada a reciclagem torna-se um importante mecanismo de redução de lixo nas grandes cidades. O Estado da Paraíba avança aos poucos em projetos e políticas públicas relacionadas à reciclagem. O número de empresas que trabalham com reciclagem no Estado ainda é considerado pouco, em vista da quantidade de resíduos que é diariamente produzido.

Reciclagem é um processo em que determinados tipos de materiais são reutilizados como matéria-prima para a fabricação de novos produtos. É um processo de extrema importância nos dias atuais porque transforma aquilo que iria ou já se encontra no lixo em novos produtos, reduzindo resíduos que seriam lançados na natureza, ao mesmo tempo em que poupa matérias-primas, muitas vezes oriundas de recursos não renováveis, e energia. Para produzir alumínio reciclado, por exemplo, utiliza-se apenas $5 \%$ da energia necessária para fabricar o produto primário. 
Muitos materiais podem ser reciclados, como o vidro, papel, plástico, metal e até mesmo o lixo orgânico, que serve como adubo para ser usado na agricultura.

Apesar de ser um processo caro, apresenta muitos benefícios, que são destacados por GRIPPI (2001):

"Melhoria das condições ambientais e sanitárias dentro do município a diminuição no volume de lixo que necessita ser aterrado, o aumento da vida útil do aterro, a economia de energia, a economia de matéria-prima virgem. Os benefícios sociais, geração de empregos diretos e indiretos, geração de renda com a venda do composto orgânico e de materiais recicláveis, o despertar do sentimento de cidadania" (GRIPPI, 2001, p. 78).

Reciclar é reaproveitar, reutilizar algo que foi rejeitado. Reciclagem é um conjunto de técnicas que tem por finalidade aproveitar os resíduos e reutiliza-los. E o resultado de uma série de atividades, pela qual, materiais que se tornariam lixo, ou estão no lixo, são desviados, coletados, separados e processados para serem usados como matéria-prima na manufatura de novos produtos, contribui para preservar o meio ambiente, para a diminuição da poluição e degradação da natureza, além de gerar riquezas e criar oportunidades de emprego e renda para muitas famílias.

Diversas organizações não governamentais (ONGs) são responsáveis por essas coletas e dão um novo destino ao lixo. São nelas onde encontramos as respostas para a viabilização ecológica, financeira e sustentável da reciclagem, pois quando reciclamos algo, deixamos de sucatear os recursos naturais que possuímos, trabalhamos com a sustentabilidade e a recuperação de áreas degradadas e a geração de emprego e principalmente dignidade para uma minoria.

Neste trabalho, vamos identificar, através de levantamento de dados bibliográfico, os principais tipos de lixo, a importância da coleta seletiva e da reciclagem; entender os mecanismos das políticas públicas e a eficiência do desenvolvimento sustentável em relação à problemática do lixo.

\section{MATERIAL E MÉTODOS}

Seguindo as orientações abordadas por Gil (2002) foram realizadas pesquisas bibliográficas em periódicos, livros e materiais eletrônicos, que abordaram os pontos ligados a reciclagem e 
suas técnicas de reaproveitamento, dentre outros, contribuindo para a ampla explanação deste tema neste artigo.

\section{RESULTADOS}

Resíduos sólidos, ou simplesmente lixo, resultam de atividades humanas e podem ser de origem industrial, doméstica, comercial, agrícola e hospitalar, entre outros (ABNT, 2004). Lixo é tudo aquilo que entrou em desuso ou é considerado sem utilidade.

Nos dias atuais, podemos definir a sociedade, como sociedade do desperdício, pois a competição industrial induz através da propaganda, o consumo desenfreado, que provoca o desperdício e o acúmulo de itens inutilizados. Vivemos a era do descartável, da modernidade, pensamento de progresso errôneo, o descartável gera consumo absurdo de matérias-primas e consequentemente o aumento exagerado do lixo.

Uma das maiores preocupações a nível mundial diz respeito à destinação daquilo que é descartado por não ter mais utilidade, o lixo. Segundo BARTONE (2001), lixo é todo material, orgânico ou não, produzido pela sociedade humana, que foi considerado inútil e indesejado e que deve ser eliminado. Pode ser definido também como aquilo que não tem valor funcional para algumas pessoas, as quais desejam tira-lo da sua vista por enxerga-lo como algo sujo e repugnante.

Atualmente, os principais destinos para o lixo são os aterros, controlado e sanitário. Denomina-se aterro o aterramento planejado dos resíduos sólidos e controlado tecnicamente, de modo a evitar a proliferação de vetores e roedores e outros riscos à saúde. Já o aterro controlado é uma técnica de disposição de resíduos sólidos no solo, visando à minimização dos impactos ambientais. Esse método utiliza alguns princípios de engenharia para confinar os resíduos sólidos, cobrindo-os com uma camada inerte na conclusão de cada jornada. Enquanto que o aterro sanitário é semelhante ao aterro controlado, porém deverá necessariamente conter sistemas de impermeabilização da base e laterais, sistemas de drenagem do chorume para tratamento, remoção segura e queima dos gases produzidos.

É necessário ainda destacar a importância do acondicionamento, coleta e transporte adequados para os diferentes tipos de lixo, contudo o que percebemos é um total descaso por parte do poder público e o resultado são lixões a céu aberto servindo como fonte de doenças.

Diante de uma situação lamentável mostrada diariamente pela mídia são de suma importância ações que tenham o objetivo de minimizar os impactos causados pelo o lixo. Devemos priorizar práticas de reaproveitamento de material reciclável, diminuindo o desperdício. 
Baseado nesta realidade, entendemos como sendo lixo:

a. Orgânicos: O lixo orgânico é resultado de descartes em residências, escolas, empresas e até mesmo da natureza, tomemos como exemplo as carnes, os vegetais, os frutos, as cascas de ovos, papel, madeira, ossos, sementes, entre outros, são a grande parte de restos dos exemplos citados que são classificados por lixo orgânico. Outro exemplo do lixo orgânico são os dejetos humano, como as fezes e urinas, que causam muitas doenças se forem eliminados em locais inadequados ou mal estruturado.

b. Não orgânicos: latas em geral, vasilhames de vidros, plásticos em geral.

c. Hospitalar: Resultado de descartes de hospitais e clínicas médicas, onde são utilizados materiais como seringas, agulhas, luvas, fraudas, sondas entre outros materiais que são na maioria das vezes descartados de forma inadequada, como por exemplo, apesar de serem classificados por lixo hospitalar, é comum serem encontrados junto com lixos de residências, onde que muitas vezes ao ser coletado trabalhadores correm o risco de se ferem e contaminam, pois esse tipo de lixo devem ser destinado à queima. A coleta também deve ser separada e feita de maneira adequada.

d. Construção Civil: demolições e restos de obras, solos de escavações, o entulho.

e. Industrial: Considerando as indústrias como sendo as principais geradoras deste lixo por meio dos restos de carvão mineral, restos de matérias-primas usadas para a fabricação de produtos, dos lixos químicos, dos gases e fumaças liberados em grandes quantidades, afetando e gerando drásticas consequências para a população e o meio ambiente. Umas das maneiras de poluição com o lixo industrial é que em particular os lixos em estado líquido são na grande maioria jogados nos rios e mares.

f. Eletrônico: equipamentos eletrônicos, por exemplo, TV, telefones móveis, computadores, baterias de celulares, entre outros aparelhos que são descartados. Esse tipo de lixo contém metais, ouro, cobre, alumínio e outros materiais. O lixo eletrônico vem causando grandes preocupações em relação à poluição, principalmente nos países emergentes onde a situação se agrava cada vez mais. O Brasil é considerado o maior produtor de lixo eletrônico entre os países emergentes, fato que aumenta as preocupações e a necessidade de conscientização.

g. Lixo atômico: é perigoso, pois os resíduos produzidos pelas usinas nucleares, como o urânio, césio, iodo, estrôncio e outros são colocados em caixas de concreto lacradas, sendo posteriormente jogadas no mar ou enterradas. Pode desencadear consequências trágicas se acontecer a corrosão dessas caixas. Uma das maiores preocupações com esse tipo de lixo é o vazamento radioativo de aparelhos de raio-X e em maiores escalas das usinas nucleares, no Japão, por exemplo, são produzidos cerca de uma tonelada de resíduos radioativos que são transportados para a França e para o Reino Unido.

h. Lixo Urbano: Significa a junção de todos os lixos, como o lixo orgânico, hospitalar, industrial, radioativo, eletrônico entre outros. Todas as atividades provenientes do ser humano, sendo nas residências, nas escolas, nas indústrias, nos hospitais e os tecnológicos.

Algumas mudanças que podem ser realizadas pelo homem e podem amenizar os problemas com lixo urbano, podemos citar: 
$\checkmark$ Reciclar, doar e ter outras finalidades para embalagens, roupas e etc.

$\checkmark$ Minimizar a produção de lixo por pessoa

$\checkmark$ Construir aterros sanitários, que seguem procedimentos de segurança, possuindo sistemas de drenagem e tratamento de resíduos.

$\checkmark$ Utilizar sacolas recicláveis, para reduzir a utilização de sacos plásticos.

Reciclar é uma expressão que vem do inglês "recycle" (re = repetir, e cycle = ciclo). Reciclagem é um termo utilizado, para indicar o reaproveitamento ou a reutilização de um polímero no mesmo processo em que foi rejeitado (Fig. 1).

O vocábulo surgiu na década de 70 , quando as preocupações ambientais passaram a ser tratadas com maior rigor, especialmente após o primeiro choque do petróleo. Foi constatado que as fontes de petróleo, que é uma matéria-prima não renovável, estavam se esgotando muito rápido, e que não havia espaço o suficiente para despejar resíduos no meio ambiente. Em meio a esses fatos, a reciclagem ganhou destaque.

Reciclar significa reaproveitar materiais beneficiados como matéria-prima para um novo produto. Podem ser reciclados vários tipos de materiais como vidro, plástico, metal e o papel. A reciclagem só serve para os materiais que podem voltar ao estado original e ser transformado novamente em produto igual em todas as suas características.

Reciclagem é um processo em que determinados tipos de materiais são reutilizados como matéria-prima para a fabricação de novos produtos. É um processo de extrema importância nos dias atuais porque transforma aquilo que iria ou já se encontra no lixo em novos produtos, reduzindo resíduos que seriam lançados na natureza, ao mesmo tempo em que poupa matérias-primas, muitas vezes oriundas de recursos não renováveis, e energia.

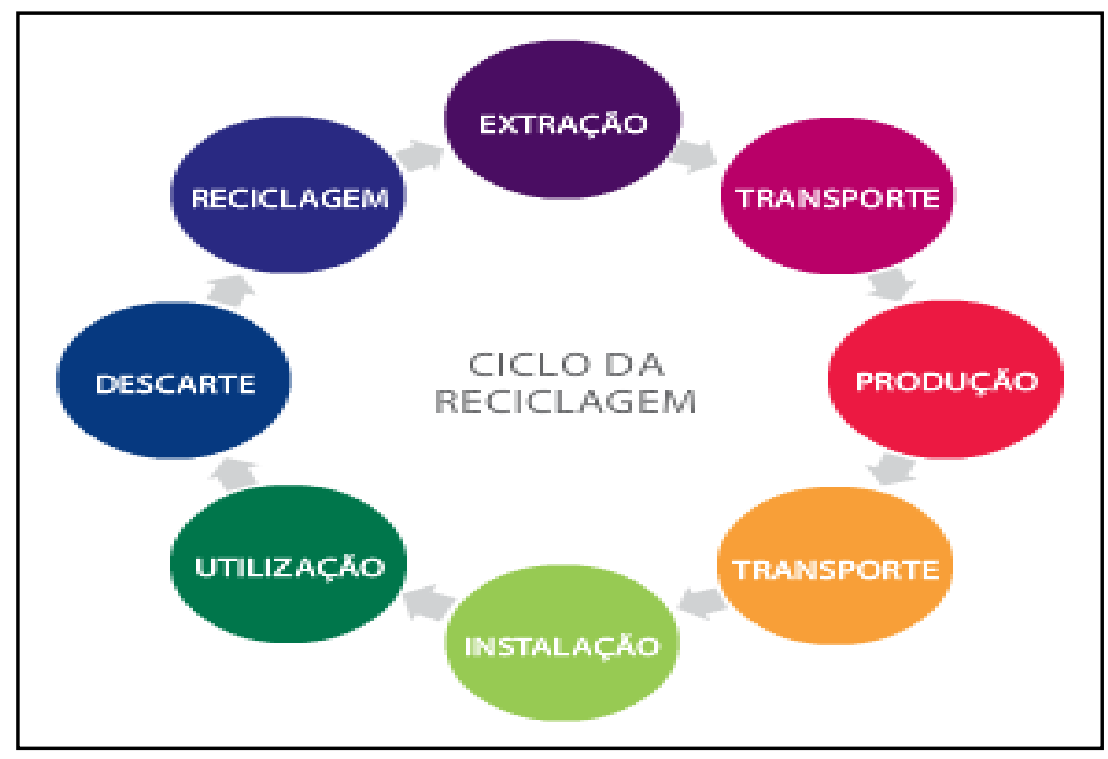

Figura 1. Ilustração do ciclo da reciclagem. Fonte: http://fuxicriando.blogspot.com/2011/. 
No Brasil, existem algumas classificações quando se diz respeito aos resíduos liberados por indústrias, fábricas, residências e hospitais. Essa classificação, regulamentada pela ABNT (Associação Brasileira de Normas Técnicas, através da NBR 10004, de SET/ 1987- RESÍDUOS SÓLIDOS), distribui os resíduos quanto aos seus potenciais riscos ao meio ambiente e à saúde pública:

Classe I - Perigosos: Apresentam periculosidade ou uma das seguintes características: inflamabilidade, corrosividade, reatividade, toxicidade e patogenicidade. Exemplos: as baterias e produtos químicos.

Classe II - Não Inertes: podem apresentar as seguintes propriedades: combustibilidade, biodegradabilidade ou solubilidade em água. Exemplos: matéria orgânica e papel.

Classe III - Inertes: Não têm constituinte algum solubilizado em concentração superior ao padrão de potabilidade de águas. Exemplos: rochas, tijolos, vidros e certos plásticos e borrachas que não são decompostos prontamente.

Essa classificação é utilizada para que a destinação dos resíduos seja correta e minimizem os impactos ocasionados por eles no ambiente.

Alternativas, diferentes da reciclagem, podem ser utilizadas para diminuir a quantidade de lixo nos aterros sanitários, entre eles temos: a compostagem, processo biológico, aeróbico e controlado, no qual a matéria orgânica é convertida pela ação de microrganismos já existentes ou inoculados na massa de resíduo sólido, em composto orgânico e a incineração, que consiste num processo de oxidação a alta temperatura, com a queima dos gases entre $1.000^{\circ} \mathrm{C}$ a $1.450^{\circ} \mathrm{C}$, no tempo de até quatro segundos, devendo ocorrer em instalações bem projetadas e corretamente operadas, onde há a transformação de materiais e a destruição dos microrganismos dos resíduos sólidos, visando, essencialmente, à redução do seu volume para $5 \%$ e, do seu peso, para $10 \%$ a $15 \%$ dos valores iniciais.

Dentro desta temática temos os produtos que podem ser reciclados, que são:

- Vidro: Podem ser inteiros ou quebrados. Os mais comuns são os potes de alimentos (azeitonas, milho, requeijão), tampas, garrafas de bebida e copos. O vidro é derretido e reutilizado, seja novamente na forma de potes ou outros objetos. Existem alguns vidros que não podem ser reciclados: espelhos, cristais, ampolas de medicamentos, vidros temperados planos.

- Papel: jornais, revistas, folhetos, caixas de papelão, embalagens de papel, aparas de papel, papel de fase, formulários de computador, folhas de caderno, cartolinas, cartões, rascunhos escritos, envelopes, fotocópias, folhetos impressos em geral. Quando o papel é reciclado ele bastante diferente daquele que o originou. O novo papel possui textura, gramatura e cor 
diferentes, pois ele é transformado em uma massa, através do processo de reciclagem, que resulta em um novo material com diferentes propriedades. Há alguns papéis que não podem ser reciclados: adesivos, etiquetas, fita crepe, papel carbono, fotografias, papel toalha, papel higiênico, papéis e guardanapos engordurados, papéis metalizados, parafinados e plastificados. - Metal: latas de alumínio (latas de bebidas), latas de aço (latas de óleo, sardinha, molho de tomate), pregos, tampas, tubos de pasta, ferragens, canos, esquadrias e molduras de quadro, cobre, alumínio. Uma lata de alumínio pode ser derretida de volta ao estado que estava antes, podendo ser transformada em lata novamente. Clipes, grampos, esponjas de aço, latas de tintas e pilhas são exemplos de metais que não podem ser reutilizados.

- Plástico: potes de plástico, potes de alimentos (margarina), frascos, utilidades domésticas, embalagens de refrigerantes, garrafas de água mineral, recipientes para produtos de higiene e limpeza, PVC, tubos e conexões, sacos plásticos em geral, brinquedos, engradados de bebidas, baldes, garrafas PET, embalagens e sacolas de supermercado. O plástico pode ser triturado para ser matéria-prima para outros produtos. Plásticos que não são reutilizados: cabos de panelas, tomadas, embalagens metalizadas (ex. alguns salgadinhos), isopor, adesivos e espuma.

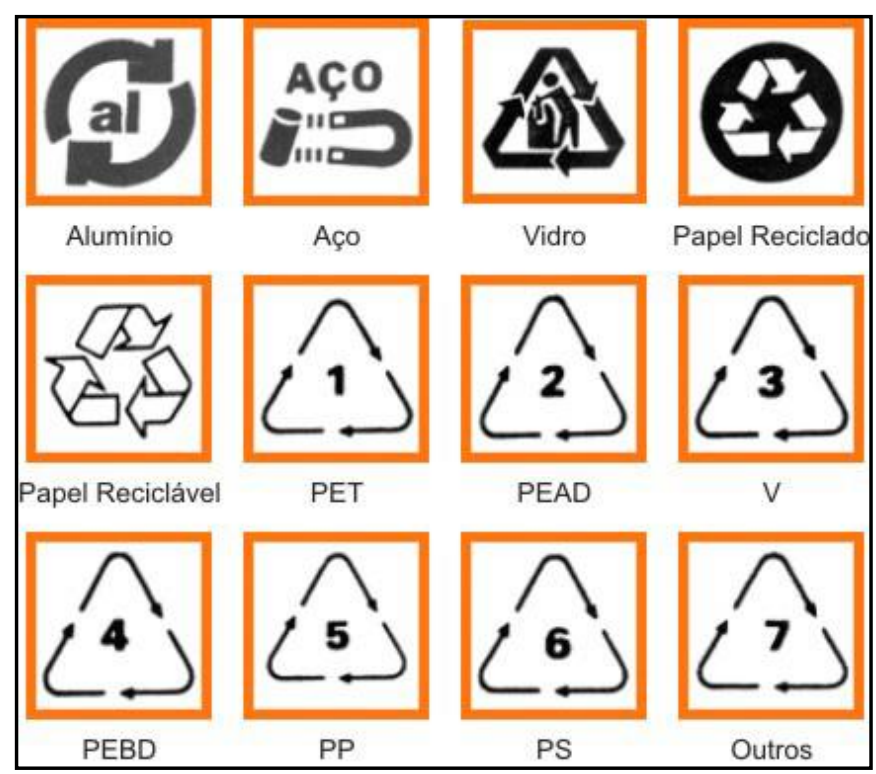

Figura 2. Símbolos utilizados para indicar a Reciclagem. Fonte: http://fuxicriando.blogspot.com/2011/.

Como pode ser observado na figura 2, cada símbolo possui o significado relativo aos elementos de acordo com as divisões da reciclagem, o 1 representa o Politereftalato de etila 
(PET), o 2, Polietileno de alta densidade (HDPE* ou PEAD), 3, Policloreto de vinila (PVC* ou V), número 4, Polietileno de baixa densidade (LDPE* ou PEBD), o 5, Polipropileno (PP), o número 6, Poliestireno (PS) e por último, o 7, que representa outros, são elementos que não se encaixam em nenhum dos anteriores.

A importância da reciclagem e da reutilização de papel vai muito além de ajudar a solucionar o problema do acúmulo de lixo, pois também contribui para a diminuição do desmatamento. A redução da quantidade de lixo nos aterros, a poluição dos rios, ar e águas, bem como a devastação florestal são outros benefícios acarretados pela reciclagem e reutilização de materiais.

É notável o uso das novas tecnologias pela nossa sociedade. Todas as mudanças nas indústrias acarretam novos empregos, aumento da lucratividade e nos produtos que nos proporcionam uma vida mais confortável. Embora o desenvolvimento tecnológico e científico e o elevado consumo possam trazer consequências desagradáveis, poluímos mais o ar, usamos mais energia, produzimos mais lixo e exploramos indiscriminadamente a natureza e seus recursos. Para tentar minimizar esses fatores de risco ambiental, inúmeras campanhas têm sido feitas pelos mais variados segmentos da sociedade, no sentido de conscientizar o ser humano da necessidade de preservação do meio ambiente, entre elas o incentivo a coleta seletiva.

A reciclagem pode ser usada no meio artístico, utilizando-se do reaproveitamento de materiais que seriam destinados ao lixo, acumulando-se nos aterros e degradando o ambiente.

O papel pode ser reciclado sendo transformados em cartões, cestas, origamis, abajur, quadros, objetos de decoração, embalagens de presentes, entre outros. Já o alumínio reciclado pode ser utilizado como objetos de decoração, dos lacres das latinhas de alumino podem ser confeccionados roupas, bijuterias, e etc.

O óleo que, não deveria, mas muitas vezes é descartado nas pias domésticas e de restaurantes, pode ser reutilizado como matéria-prima na fabricação de sabão.

As garrafas PET podem ser utilizadas como vassouras, objetos de decoração, bijuterias. Já o lixo orgânico, pode ser destinado à fertilização de jardins, praças e pequenas plantações, melhorando naturalmente o solo.

O lixo eletrônico, principalmente celulares e computadores, é desmontado e suas peças se tornam matéria-prima para novos produtos do ramo ou há o reaproveitamento e a reutilização destes componentes.

A base da reciclagem recorre à ação dos três R's: Reduzir, Reutilizar e Reciclar. 
Para a sobrevivência da natureza é necessário que o homem se conscientize das suas práticas que estão degradando o ambiente. Uma delas é a alta produção de lixo. Para minimizar esse problema, poderíamos reduzir a quantidade de produtos que consumimos, sejam eles alimentos, roupas, entre outros, pois muitas vezes acumulamos objetos sem nenhuma finalidade e quando resolvemos descarta-lo, ele vai para onde? Lixo!

Além disso, as empresas poderiam cortar gastos se reduzissem a compra ou utilização de alguns componentes. Por exemplo, uma indústria poderia criar meios de reutilizar água, fazendo uma recirculação, reduzindo, assim, o consumo de água.

Reutilizar materiais é uma maneira prática e criativa de transformar um objeto que antes era considerado inútil em algo inovador e evitar o aumento do acúmulo de lixo nos aterros. Utilizando-se da criatividade e imaginação podemos criar a partir de vidros de geleia e maionese, por exemplo, potes para guardar algodão, remédios, entre outros.

Reciclar significa transformar materiais usados em novos produtos e destina-los para o consumo. No processo de reciclagem, que além de preservar o meio ambiente também gera outros benefícios, como a geração de emprego e renda para as pessoas que se dedicam a esse trabalho. Os materiais mais reciclados são o vidro, o alumínio, o papel e o plástico. Além disso, a reciclagem contribui para a diminuição significativa dos diversos tipos de poluição e, quando adotada por empresas e indústrias, torna-se uma forma de reduzir os custos de produção.

Dentre outros, citamos os principais benefícios da Reciclagem: economia de energia, redução da poluição, geração de empregos, melhoria da limpeza e higiene da cidade, diminuição do lixo nos aterros e lixões, diminuição da extração de recursos naturais e a decrescente redução de florestas nativas.

Para minimizar os efeitos do acumulo dos lixos nos aterros sanitários, uma ideia que vem sendo bastante utilizada é a coleta seletiva de materiais. Separar os materiais reutilizáveis, para que não sejam encaminhados juntamente com aquele que não pode ser reciclado, saturando ainda mais os aterros sanitários e lixões, é uma forma de dar outro destino ao lixo.

A coleta seletiva é um processo que consiste na separação e recolhimento de resíduos descartados. Os materiais que podem ser reciclados são separados do lixo orgânico (restos de carne, frutas, verduras e outros alimentos), estes são descartados em aterros sanitários ou usados para a fabricação de adubos orgânicos.

A coleta seletiva associada à reciclagem de lixo é de suma importância para o meio ambiente, pois através delas, recuperam-se matérias-primas, que outrora seriam retiradas 
novamente da natureza. A elevada exploração dos recursos naturais não renováveis aumenta a necessidade de reaproveitamento dos materiais recicláveis, que podem separados na coleta seletiva de lixo, ou seja, um sistema de recolhimento de materiais recicláveis: papéis, plásticos, vidros, metais e orgânicos, que podem ser reutilizados ou reciclados. A reciclagem gera economia de matérias-primas, água e energia, é menos poluente e alivia os aterros sanitários, cuja vida útil é aumentada, poupando espaços preciosos da cidade que poderiam ser usados para outros fins como parques, casas, hospitais, etc.

O lixo produzido nas residências, empresas e indústrias são destinados, muitas vezes, para aterros sanitários, onde lá os agentes ambientais fazem a coleta e separação de materiais recicláveis, como plástico, vidro, metais e outros. Essa separação de materiais costuma ser feita de duas maneiras:

a) Coleta comum, seguida de triagem - a separação dos materiais é feita em pontos de triagem ou no próprio lixão. Os resíduos chegam ao local de descarte muito misturados com lixo orgânico, o que aumenta sua contaminação.

b) Coleta seletiva de reciclados - nesse tipo de coleta não há mistura dos materiais com o lixo orgânico. A coleta seletiva visa quatro produtos principais: papel, plástico, vidro e metal.

Além de gerar renda para milhões de pessoas e economia para as empresas, a coleta seletiva é importante, pois ajuda a preservar o meio ambiente, uma vez que diminui a poluição dos rios e solos, também contribui para o desenvolvimento sustentável do planeta.

Para facilitar a separação dos resíduos, depósitos são produzidos com cores diferentes para a identificação de produtos recicláveis. Podemos citar:

- Amarelo: Metal - latas de refrigerante e de conservas em geral, panelas sem cabo, canos, pregos podem ser descartados nesse recipiente. Porém, as latas de tinta, verniz, solventes químicos, aerossóis, pilhas, esponjas de aço e clipes não podem reciclados.

- Azul: Papel - jornais, revistas, envelopes, livros, cadernos, caixas de papelão, listas telefônicas, impressos em geral, embalagens longa vida. Devem ter outro destino os papéis higiênicos, engordurados, cigarros, guardanapo sujos, etiquetas, fitas crepe, papéis parafinados, fotos, carbono.

- Cinza: resíduos não-recicláveis.

- Laranja: resíduos perigosos.

- Marrom: resíduos orgânicos.

- Preto: madeira.

- Roxo: resíduos radioativos. 
- Verde: Vidro - garrafas, potes de conserva, frascos de remédio, vidros de perfume, copos, cacos desses produtos devidamente embalados podem ser reciclados. Porém, os para-brisas, lâmpadas, boxes temperados, espelhos, louças, cerâmicas, espelhos, cristais, ampolas de injeção e pirex não podem ser reutilizados.

- Vermelho: Plástico - garrafas de bebidas em geral, frascos de produtos de limpeza e higiene, sacolas e sacos, tampas de recipientes, peças plásticas de brinquedos, copos. Já as fraldas descartáveis, isopores, fitas adesivas, cabos de panela devem ser destinados diferentemente.

- Branco: resíduos ambulatoriais e de serviços de saúde.

As cores mais comuns estão representadas na figura abaixo (Fig. 3):

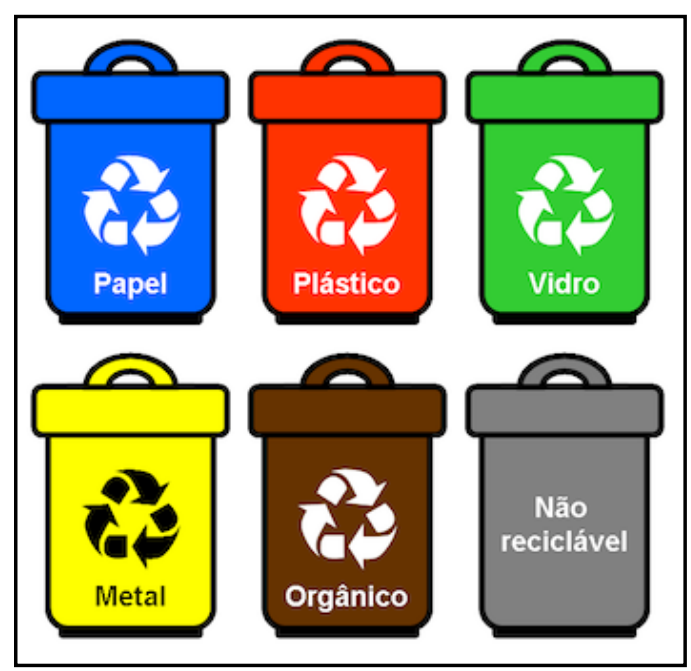

Figura 3. Lixeiras com cores e suas representações. Fonte: http://fuxicriando.blogspot.com/2011/.

Quanto aos descartes apropriados, temos:

a) Lâmpadas fluorescentes: no interior dessas lâmpadas, possui o vapor de mercúrio, gás tóxico, que contamina o ar quando quebrada. Desta forma necessita de descarte especial. Algumas lojas de materiais elétricos e de construção possuem pontos de coleta destes tipos de materiais.

b) Pilhas, baterias comuns e de celular, quando descartados no meio ambiente, provocam contaminação do solo. Estes materiais podem ser deixados em pontos de coletas em algumas empresas.

c) Medicamentos não devem ser descartados junto com o lixo orgânico, pois possuem substâncias químicas que podem contaminar o solo e a água. Algumas reses de farmácias possuem pontos de coleta de medicamentos que não são mais usados. 
d) Lixo hospitalar: costumam estar infectados com grande quantidade de bactérias e vírus. Desta forma são retirados dos hospitais com procedimentos seguros e levados para a incineração em locais especiais.

"É a forma como as atuais gerações satisfazem as suas necessidades sem, no entanto, comprometer a capacidade de gerações futuras satisfazerem as suas próprias necessidades" (BRUNDTLAND apud SCHARF, 2004, p.19). Significa possibilitar que as pessoas, agora e no futuro, atinjam um nível satisfatório de desenvolvimento social e econômico e de realização humana e cultural, fazendo ao mesmo tempo, um uso razoável dos recursos da terra e preservando as espécies e os habitantes naturais.

Inúmeros são os conceitos e definições atribuídas ao desenvolvimento sustentável, mas são os seus objetivos e diretrizes devem nortear governantes, empresas e indústrias que queiram adotar a sustentabilidade.

Em 1986 a Conferência de Ottawa (CARTA DE OTTAWA, 1986) estabeleceu cinco requisitos para se alcançar o desenvolvimento sustentável:

- integração da conservação e do desenvolvimento;

- satisfação das necessidades básicas humanas;

- alcance de equidade e justiça social;

- provisão da autodeterminação social e da diversidade cultural;

- manutenção da integração ecológica.

Já entre os anos de 1988 e 1991, a Comissão Mundial do Meio Ambiente e Desenvolvimento demonstrou que os objetivos que derivam do conceito de desenvolvimento sustentável estão relacionados com o processo de crescimento da cidade e deve ter por base a conservação do uso racional dos recursos naturais incorporados às atividades produtivas. Entre esses objetivos estão:

- Crescimento renovável;

- Mudança de qualidade do crescimento;

- Satisfação das necessidades essenciais por emprego, água, energia, alimento e saneamento básico;

- Garantia de um nível sustentável da população;

- Conservação e proteção da base de recursos;

- Reorientação da tecnologia e do gerenciamento de risco;

- Reorientação das relações econômicas internacionais (CMMAD, 1988, 1991).

O desenvolvimento sustentável, para quem deseja adota-lo, fundamenta-se em três bases: a econômica, a social e a ambiental. A base econômica relaciona-se diretamente a 
rentabilidade da empresa que, por exemplo, resolva adotar o desenvolvimento sustentável. Ela deve avaliar os custos das atividades que são economicamente sustentáveis e a lucratividade que essa nova metodologia de trabalho irá trazer.

A base social, questionada por inúmeros autores, perpassa pela realidade da desigualdade social vivida pelo país. Eles acreditam que se o sistema social não estiver progredindo como um todo, a questão ambiental e também a economia não irão progredir de maneira desejada. Enquanto que a base ambiental, a empresa deve ser avaliada constantemente se sua produção é viável ecologicamente. Segundo Elkington (2001), as empresas precisam: identificar quais as formas de capital natural impactadas pelas suas operações, avaliar se elas são sustentáveis, se o nível de estresse causado é sustentável e, finalmente, se o equilíbrio da natureza está sendo afetado de forma significativa.

Em diversos aspectos o desenvolvimento sustentável se assemelha a sustentabilidade. Esta apresenta é um conceito sistêmico, relacionado com a continuidade dos aspectos econômicos, sociais, culturais e ambientais da sociedade humana.

A sustentabilidade propõe um meio de orientar a civilização e atividade humanas, de tal forma que a sociedade, os seus membros e as suas economias possam preencher as suas necessidades e expressar o seu maior potencial no presente, e ao mesmo tempo preservar a biodiversidade e os ecossistemas naturais, planejando e agindo de forma a atingir próeficiência na manutenção indefinida desses ideais. Esse conceito pode ser abrangido em sustentabilidade ambiental, sustentabilidade econômica e sustentabilidade sociopolítica.

O desenvolvimento sustentável para ser alcançado depende de reconhecimento e planejamento. Além disso, deve saber usar os recursos naturais com critério e respeito ao próximo e ao meio ambiente, preservar a natureza e a dignidade humana, desta forma, planejar novos modelos de desenvolvimento econômico para a humanidade.

Confunde-se bastante o desenvolvimento com crescimento econômico. Desenvolvimento que depende do consumo crescente de energia e recurso naturais, que as atividades econômicas são incentivadas em detrimento ao esgotamento dos recursos naturais do país, é involução. É insustentável e está fadado ao insucesso. Desenvolvimento sustentável está relacionado à qualidade, ao invés da quantidade, com a redução de matéria- prima e produtos. Implica em mudanças nos padrões de consumo e do nível de conscientização.

O desenvolvimento sustentável significa obter crescimento econômico necessário, garantindo a preservação do meio ambiente e o desenvolvimento social. Para Canepa (2007, apud BARBOSA, 2008) “o desenvolvimento sustentável caracteriza-se, portanto, não como um estado fixo de harmonia, mas sim como um processo de mudanças, no qual se 
compatibiliza a exploração de recursos, o gerenciamento de investimento tecnológico e as mudanças institucionais com o presente e o futuro". (p. 6)

Para BARBOSA (2008), a sustentabilidade consiste em encontrar alternativa de produção, distribuição e consumo dos recursos existentes de forma mais eficiente, economicamente e ecologicamente viável. Priorizar o desenvolvimento social e humano com capacidade de suporte ambiental, gerando cidades produtoras com atividades que podem ser acessadas por todos é uma forma de valorização do espaço incorporando os elementos naturais e sociais.

Resíduo sólido tem sido um dos maiores problemas enfrentados pela humanidade. Em termos financeiros apresenta um gasto médio de $18 \%$ dos orçamentos municipais. Já em termos ambientais tem sido responsável pela degradação ambiental, com a liberação do chorume que contamina o lençol freático, a emissão de gases que provocam o efeito estufa ( $\mathrm{CH} 4$ e CO2), e com a proliferação de vetores como baratas e ratos que provocam doenças.

A regulamentação da nova lei vinha sendo debatida há mais de 20 anos pelo Congresso Nacional e o projeto, agora aprovado, reúne princípios, objetivos, instrumentos e diretrizes para a gestão dos resíduos sólidos no Brasil.

A lei faz distinção entre resíduos (lixo que pode ser reaproveitado, ou reciclado), e rejeito (o que não é passível de reaproveitamento), gerado pelo setor doméstico, saúde e indústria. Entre outros itens, o documento prevê destinação adequada dos eletrônicos, incluindo baterias de celulares e computadores obsoletos. De acordo com essa medida, as empresas produtoras ficam obrigadas a recolher produtos descartados. A lei estabeleceu a integração de municípios na gestão dos resíduos e responsabiliza toda a sociedade pela geração de lixo.

Com 58 artigos que ocupam 43 páginas, o texto proíbe a criação de lixões, nos quais os resíduos são lançados a céu aberto. Após a sanção presencial, todas as prefeituras deverão construir aterros sanitários adequados ambientalmente, onde só poderão ser depositados sem qualquer possibilidade de reaproveitamento ou compostagem.

O Decreto de regulamentação da Lei prevê a obrigação dos consumidores a separar (reciclar) o resíduo sólido, instituindo multa (art.84): $§ 2^{\circ}$ - estarão sujeitos à penalidade de advertência; $\S 3^{\circ}$ - penalidades de multa, no valor de $\mathrm{R} \$ 50,00$ (cinquenta reais) a $\mathrm{R} \$ 500,00$ (quinhentos reais); o titular do serviço público (Municipal) deverá implantar no mínimo a separação de resíduos seco e úmido e implantar a reciclagem; o município priorizará a participação de cooperativas ou de outras formas de associação de catadores de materiais reutilizáveis constituídas por pessoas de baixa renda (gestão compartilhada). 
Políticas públicas sobre reciclagem vêm sendo discutidas em fóruns realizados no Estado da Paraíba. No ano de 2009 durante o Fórum de Serviço Social, presidentes de cooperativas de catadores de materiais recicláveis de Campina Grande, afirmaram que a crise econômica afetou seu trabalho e sustento, na medida em que eles passaram a receber muito menos pelo mesmo material recolhido. Eles também salientam que esperam providências dos governos municipal e estadual para que estes implantem políticas públicas de coleta seletiva e material reciclável na cidade.

José Cardoso (Cooperativa Pró-Recife e representante do Nordeste Movimento Nacional dos Catadores) revelou que mesmo antes da mais recente crise financeira que abalou o Brasil e o mundo, os catadores já sofriam dificuldades. Porém mostrou em números que a crise não poupa quase ninguém. Ela afetou desde o grande empresário ao catador de lixo, figura que tem seu importante papel na sociedade, porém é agente invisível para a maioria. Antes da crise os papelões eram vendidos por toneladas $\mathrm{R} \$ 24$ e hoje os atravessadores e empresas oferecem por tonelada apenas $\mathrm{R} \$ 8$.

Na cidade de Campina Grande, por exemplo, esse Decreto não está sendo realizado como em Recife, onde o Decreto é atuante. Desta forma, há uma preocupação com relação ao desenvolvimento da reciclagem.

Pesquisas revelam que o Estado da Paraíba se encontra na última posição no ranking de coleta seletiva. João Pessoa possui Políticas Públicas de reciclagem com índice de 0,1\%, difere totalmente da realidade do Rio Grande do Sul, que ocupa o primeiro lugar com índice de $29,6 \%$ de projetos ambientais de reciclagem.

Segundo a Curadoria Estadual do Meio Ambiente, apenas quatro cidades paraibanas (João Pessoa, Cajazeiras, Patos e Alagoa Grande) contam com aterros sanitários. O restante destas verdadeiras montanhas de sobras é jogado a céu aberto.

Outro projeto vem sendo desenvolvido no Estado da Paraíba, especificamente no Município de Sertãozinho, onde teve no dia 30 de novembro de 2010 no auditório Nereu Ramos, na Câmara dos Deputados, em Brasília - DF, sua premiação, que foi promovida pela Comissão de Desenvolvimento Urbano da Câmara dos Deputados. Este projeto tem como objetivo a implementação da coleta seletiva de resíduo sólido no Município de Sertãozinho, coordenado pelo Extensionista Tarcísio Valério da Costa.

Inúmeros são os métodos capazes de melhorar o estado de exploração e degradação do meio ambiente nos dias atuais. Dentre eles, existe um que é capaz de propiciar além de benefícios ambientais, acarreta vantagens social e econômica: a reciclagem. 
"Reciclar significa transformar os restos descartados pelas residências, fábricas, lojas e escritórios em matéria-prima para a fabricação de outros produtos. Não importa se o papel está rasgado, a lata amassada ou a garrafa quebrada. Ao final, tudo vai ser dissolvido e preparado para compor novos objetos e embalagens. A matéria orgânica também pode ser reciclada, mas é através do processo de compostagem que ela virará adubo orgânico. " (RODRIGUES; CAVINATO, 1997, p. 58).

Associado a reciclagem, uma alternativa que deve ser trabalhada conjuntamente é a coleta seletiva de materiais, que garantem sustentabilidade financeira aos participantes e proteção ao ambiente. Como processo que visa a redução de resíduos, a reciclagem engloba questões nos âmbitos econômico, social e ambiental, pois a capacidade poluidora do lixo envolve a triste realidade da degradação social das famílias que sobrevivem do reaproveitamento de materiais e do potencial econômico, pouco explorado, por parte dos empresários e governantes, da reutilização de materiais.

Sendo assim, MONTEIRO e colaboradores (2001) definem que reciclagem é o resultado de uma série de atividades através do qual, materiais que se tornariam lixo, ou estão no lixo, são coletados, separados e processados parem usados como matéria-prima na manufatura de bens, feitos anteriormente apenas com matéria-prima virgem.

Em consonância, DUSTON (1993 apud CALDERONI, 2003a) demonstra um conceito ainda mais profundo a respeito da reciclagem: processo através do qual qualquer produto ou material que seja considerado inutilizável para o fim que lhe foi atribuído tenha sido separado do lixo é reintroduzido no processo produtivo e transformado em um novo produto, seja igual ou semelhante ao anterior.

A reciclagem, por maior que seja sua importância ambiental e econômica, não pode desenvolver-se de modo repentino, sem planejamento (CALDERONI, 2003).

É conhecido que a reciclagem de diversos materiais com a separação do lixo urbano traz vários benefícios ambientais, sociais e econômicos para a sociedade como por exemplo redução do volume do lixo coletado, geração de empregos através de pessoas que catam e separam o lixo. Com a reutilização de materiais advindos da reciclagem diminui-se o impacto ambiental e, principalmente, gera postos de trabalho e renda. O Brasil apresenta elevados índices de reciclagem, pois tem desenvolvido estratégias próprias para incentivar o crescimento dessa atividade e aumentar a participação da população, contribuindo ainda mais, para o reaproveitamento de materiais (CESAR; de PAULA; KROM, 2004). 
Ainda de acordo com Cesar, de Paula e Krom (2004):

“[...] A reciclagem pode originar benefícios econômicos e sociais significativos: poupanças em nível de consumo de recursos ou de espaço em aterros, redução da poluição, aumento da eficiência de outros processos como a compostagem ou a incineração, e a possibilidade de permitir aos cidadãos uma participação ativa na melhoria da qualidade do ambiente" (CESAR; de PAULA; KROM, 2004, p. 1).

É fato que a reciclagem é ambientalmente viável e economicamente sustentável e essa estratégia de minimizar os impactos do lixo sobre as cidades devem ser estimulados pelos governantes. Uma das formas de organização de pessoal para trabalhar com reciclagem é a criação de cooperativas de catadores.

Segundo WIEGO (2009), os catadores de material reciclável desempenham um papel significativo nos países em desenvolvimento. Dentre os benefícios que resultam da coleta de material reciclável, além da geração de renda para os trabalhadores envolvidos, pode-se citar: a contribuição à saúde pública e ao sistema de saneamento; o fornecimento de material reciclável de baixo custo à indústria; a redução nos gastos municipais e a contribuição à sustentabilidade do meio ambiente, tanto pela diminuição de matéria-prima primária utilizada, que conserva recursos e energia, como pela diminuição da necessidade de terrenos a serem utilizados como lixões e aterros sanitários.

Além disso, as cooperativas de reciclagem representam meio de inclusão social, ascensão econômica e minimização dos problemas ambientais decorrentes do lixo, apresentando efeitos nas três dimensões básicas da sustentabilidade, a saber: econômico, social e ambiental.

O econômico refere-se aos ganhos financeiros obtidos a partir da coleta seletiva de materiais recicláveis e práticas de reciclagem para venda na cooperativa, gerando emprego e participação social. Já no âmbito social diz respeito aos ganhos recebidos pela sociedade a partir de atividades envolvidas com a reciclagem, além da autonomia financeira dos cooperados, deixando de serem muitas vezes moradores de ruas, por exemplo. E por fim, o ambiental, que se relaciona com a minimização dos problemas ocasionados ao meio ambiente a partir da incorreta disposição e utilização do lixo, diminuição da poluição, dentre tantos fatores que de forma significativa impactam no planeta.

Dentre as principais contribuições dos catadores na mitigação do impacto ambiental provocado pelos resíduos, destacam-se: diminuição da poluição decorrente da disposição 
incorreta dos resíduos sólidos urbanos; a redução do gasto de energia; e diminuição da extração de matéria-prima virgem, com a integração do material reciclado como matériaprima secundária na cadeia produtiva, dentre outros.

O nosso país Brasil tem obtidos bons resultados, conforme serão demonstrados a seguir por meio de informações obtidas junto ao CEMPRE (Compromisso Empresarial para Reciclagem). Por exemplo: 47\% do papel que circulou no País em 2006 retornou à produção da reciclagem. Esse índice corresponde a aproximadamente 1,332 milhões de toneladas de papel de escritório.

Portanto, a viabilidade da reciclagem, não apenas no Estado da Paraíba, mas em todo o Brasil e nos demais países é possível, desde que haja planejamento e metas sejam traçadas para que o objetivo principal seja atingido: melhoria nas condições financeiras dos agentes de reciclagem, minimização dos impactos ambientais ocasionados pelo lixo, redução dos lixões e aterros e uma vida sustentável em todas as suas esferas.

\section{CONCLUSÕES}

Ainda há muito a se preocupar com o futuro do meio ambiente no Estado da Paraíba, pois são poucas as iniciativas e políticas públicas dos governantes no que diz respeito com a reciclagem e reaproveitamento do lixo.

Portanto, o homem tem nas mãos a oportunidade de mudar o mundo em que vive, sabendo utilizar as riquezas que tem, transformando o lixo em luxo e conquistando o sonhando desenvolvimento sustentável do planeta Terra.

\section{REFERÊNCIAS}

ASSOCIAÇÃO BRASILEIRA DE NORMAS TÉCNICAS. NBR 10004: resíduos sólidos. Classificação. Rio de Janeiro, 2004. 77p.

BARBOSA, G.S. O desafio do desenvolvimento sustentável. Revista Visões $4^{\text {a }}$ Edição, v. 1, n. 4, p. 1-11. Jan/Jun., 2008.

BARTONE, C. Infrastructure Note W\&S NA UE-3. World Bank, Washington, USA, 2001.

BIANCHINI, T. Coleta seletiva é a saída. Ecologia e Desenvolvimento. Rio de Janeiro, v. 11, n. 96, p. 20, set. 2001. 
BRANCO, S.M. Poluição: A morte de nossos rios. São Paulo: ASCETESB, 1983.

BRUNDTLAND, G.H. Nosso futuro comum: Comissão Mundial sobre Meio Ambiente e Desenvolvimento. 2. ed. Rio de Janeiro: Fundação Getúlio Vargas, 1991.

CALDERONI, S. Os bilhões perdidos no lixo. ln: Há espaço para tanto lixo? 4. ed.

São Paulo: Humanitas/FFLCHUSP. p. 95-96, 2003.

CALDERONI, S. Os bilhões perdidos no lixo. ln: O mercado de reciclagem e o papel do governo. 4. ed. São Paulo: Humanitas/FFLCHUSP. 303-318, 2003.

CANEPA, C. Cidades Sustentáveis: o município como lócus da sustentabilidade. São Paulo: Editora RCS, 2007.

CARTA DA TERRA. Organização das Nações Unidas, 2002.

CARTA DE OTTAWA. Primeira Conferência Internacional sobre a Promoção da Saúde. Ottawa, 1986. Disponível em www.opas.org.br Acesso em novembro de 2007.

CEMPRE - Compromisso Empresarial para a Reciclagem. 2009. Disponível em: http://www.cempre.org.br/. Acesso em: 5 fev. 2018.

CESAR, A.P.; DE PAULA, D.A.; KROM, V. Importância da reciclagem de vidro. VIII Encontro Latino Americano de Iniciação Cientifica e IV Encontro Latino Americano de Pós-Graduação - Universidade do Vale do Paraíba. 2004. Disponível em: http://www.inicepg.univap.br/cd/INIC_2004/trabalhos/inic/pdf/IC6-17.pdf. Acesso em: 11 set. 2018.

COMPROMISSO EMPRESARIAL PARA RECICLAGEM (CEMPRE). Latas de Alumínio o mercado para reciclagem. Disponível em: http://www.cempre.org.br/fichas_tecnicas_latas_aluminio.php Acesso em: 11 set. 2018.

ELKINGTON, J. Canibais com garfo e faca. São Paulo: Makron Books, 2001. 
FANDINI, P.S.; FANDINI, A.A.B. Lixo: desafios e compromissos. Cadernos Temáticos de Química Nova na Escola. Edição especial. Maio 2001.

GIL, A.C. Como elaborar projetos de pesquisa. 4. ed. São Paulo: Atlas, 2002.

GRIPPI, S. Lixo, reciclagem e sua história: guia para as prefeituras brasileiras. Rio de Janeiro: Interciência, 2001. 134 p.

MONTEIRO, J.H.P.; ZVEIBIL, V.Z. Manual integrado de gerenciamento de resíduos sólidos. Rio de Janeiro: IBAM, 2001. 204 p.

RODRIGUES, F.L.; CAVINATTO, V.M. Lixo: de onde vem? Para onde vai? Editora Moderna: 1997, p. 58.

SCHARF, R. Manual de Negócios Sustentáveis. São Paulo, Amigos da Terra, 2004.

WIEGO - WOMEN IN INFORMAL EMPLOYMENT: GLOBALIZING AND ORGANIZING. Enfocándonos en las trabajadoras informales: recicladoras de basura. Cambridge. Disponível em: http://www.wiego.org/WIEGO_En_Espanol/publicaciones/FactSheet-Rec-Spanish.pdf Acesso em: 20 Maio. 2011. 